Research Article

\title{
Differential Dynamic Evolutionary Model of Emergency Financial Service Supply Chain in Natural Disaster Risk Management
}

\author{
Shujian $\mathrm{Ma}^{1,2}$ \\ ${ }^{1}$ School of Physical and Mathematical Sciences, Nanjing Tech University, Nanjing 211816, China \\ ${ }^{2}$ School of Economics and Management, Nanjing Tech University, Nanjing 211816, China \\ Correspondence should be addressed to Shujian Ma; shujianma@njtech.edu.cn
}

Received 28 April 2016; Accepted 22 June 2016

Academic Editor: Miguel Ángel López

Copyright ( $\odot 2016$ Shujian Ma. This is an open access article distributed under the Creative Commons Attribution License, which permits unrestricted use, distribution, and reproduction in any medium, provided the original work is properly cited.

A government-market-public partnership (GMPP) could be a feasible arrangement for providing insurance coverage for natural disaster. Firstly, we put forward GMPP management mode. Secondly, the emergency financial service supply chain for natural disaster risk is built from the view of supply chain. Finally, the objective of this paper is to obtain insights into the cooperative and competitive relationship in GMPP system. We establish the cooperative and competitive differential dynamic evolutionary models and prove the existence of equilibrium solutions in order to solve the coordination problems. In conclusion, the equilibrium solutions can be achieved among the insurers, the operating governments, and the public.

\section{Introduction}

Over the past century, human society has witnessed the dramatic growth of the population in natural disaster stricken areas and the vulnerability of human settlements. And it is believed that the growth of flood disaster loss results from human decisions and human economic activities to a great extent [1]. Recent extreme weather events, such as Hurricane Katrina in August 2005 and the Tsunami in Japan in 2011, have raised questions about the responsibilities of the public and the insurance company with respect to giving enough financial compensation for natural disaster losses [24]. In an attempt to make the catastrophe risk insurance [5] coverage available at an affordable price, most of the existing catastrophe risk insurance systems, such as those for floods and earthquake, have been provided as a public-private (PP) insurance plan, with some sort of involvement of the government. The government plays a role in regulating the insurance market. In order to set the regulatory scheme, the government actively shares risks in a PP insurance system by compensating through public reinsurance or a state guarantee $[6,7]$. The possible roles and responsibilities of the government for extreme natural disaster are discussed in Paudel [8].
Irrespective of scale of natural disaster, there is an urgent need for coordination efforts of efficient and effective countermeasure selection based on the evaluation of preand postevent strategies. In general, one country's economic power prior to the disaster can affect the loss caused by natural disaster to some extent. Developing countries with limited and vulnerable economies are thus suffering more severely than developed countries do, when extreme natural disaster occurs. Moreover, limited resources available will hinder the country from employing possible correct strategies, by which the policy makers and decision analysts can efficiently evaluate the situation and make loss spreading policies.

China is one of the developing countries in the world. And China is one of the countries with the most serious natural disasters in the world [9-11]. But until now, there are no more perfect corresponding financial tools such as independent insurance or bond to share the risk of natural disaster $[12,13]$. Although the hydraulic engineering construction in China could play some certain roles in natural disaster prevention, it would not be the only method taken by the government to protect property and human lives from those natural disasters. So necessary nonengineering measures should be 


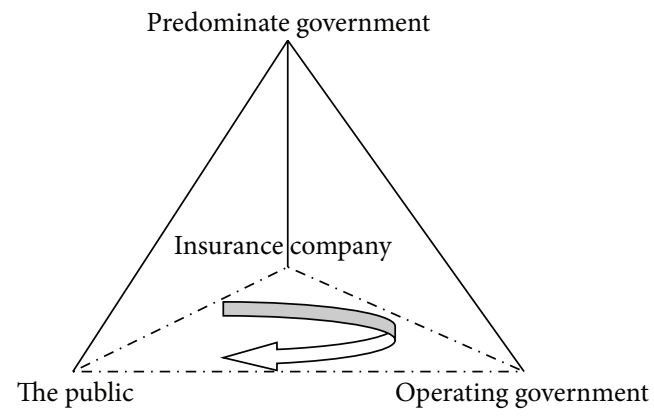

Figure 1: Structure of extreme natural risk management led by government.

made to control or share the natural disaster risk effectively. In order to design a well-functioning, either public or PP, government, it is necessary to understand the risk sharing among different partners [14], especially among the government, the insurance market, and the public. In this paper, we build the cooperative and competitive relationship among the government, the insurance market, and the public. Here we call this management mode GMPP (government, market, and public partnership). The structure of this management mode is shown in Figure 1.

For the adequate functioning of the cooperative-competitive mode system, the public should be aware of the risk that they face and of what it costs to insure such risk in order to decide whether or not to purchase insurance. In particular, we assume that the public minimize their costs (premiums to be paid) in deciding on the amount of insurance to purchase. For the insurers, it is essential that they should assess the extent of the natural disaster risk involved in the participation in this mode system so that they could make premiums that are enough to cover the potential damage. Some methods in engineering have been used in estimating the risk of the natural disaster [15-17]. We here assume that the insurers aim to minimize the premium and limit their own risk to a predefined level. And the government, who will be in a leading position to make policy and set some operating governments in charge with the operation of this system, should facilitate the sufficient functioning of this system while taking into account their own public responsibility and provide the coverage for natural disaster for public budget. To reach a better coordination result, we assume that the relationship among the operating governments is cooperation and the relationship is competition among the insurers. The differential dynamic cooperation-competition evolutionary model has been built to discuss the two kinds of relationships. The proofs in detail are shown in Section 2.

In this cooperative-competitive mode system for natural disaster, the insurer can set reasonable premium and provide insurance to the public. The public can accept and purchase the insurance. And the operating governments can make system plan to decide the distribution and premium of the insurance to satisfy the demand of the public in order to reach the public responsibility. And the operating governments are leaders among them. From the view of the financial service supply chain [18-20], the operating governments, the insurance companies, and the public are the members in this supply chain. The products of this supply chain are a series of insurances which are one kind of financial service. This supply chain starts from the insurers which are the insurance providers. And the operating government in the middle is the financial service integrator and the public are regarded as the customers. The structure is shown in Figure 2.

The current research analyzes the risk sharing system and some pricing models in detail. But literature is lacking regarding illustrating the reason why and on what condition the operating governments can cooperate, the insurance companies can compete, and the cooperative relationship can exist between operating governments and insurers. This paper will mainly discuss the cooperative relationship in the operating government on some specific conditions and the competitive relationship among the insurers in dynamics differential evolutionary model from the perspective of financial service supply chain management. In Section 2, we put forward one differential dynamic cooperation-competition evolutionary model.

\section{Differential Dynamic Cooperation- Competition Evolutionary Model}

The operating governments, the insurers, and the public are the members in a financial service supply chain whose product is a sort of insurance product in financial service. The financial service helps share the loss risk of the natural disaster. Here we assume that this particular supply chain is defined as emergency financial service supply chain. And the insurance companies, the operating governments, and the public stand for the financial service provider, the financial service integrator, and the customer, respectively.

In general, we assume that there are $N$ insurers, $K$ operating governments, and $M$ public in this emergency financial service supply chain. In this service supply chain, the insurers play the role of financial service providers who should compete with each other in order to keep the insurance market balanced development, the operating governments are the integrators who should cooperate with each other for efficient working and social responsibility, and the public are the customers who are willing to accept one kind of financial service when the balance is reached between the insurers and the operating governments. The public can get the insurance claim from insurers. And it is the governments' responsibility to give the subsidy to increase the recovery ability for the public.

The equilibrium state in the competition-cooperation dynamic system is going to be discussed in the following section.

Fundamental variables set are the following:

$x_{i}$ : profit of insurer $i, i=1,2, \ldots, N$.

$y_{k}$ : social utility of operating government $k, k=$ $1,2, \ldots, K$.

$r_{i}$ : interests of the pure growth rate for insurer $i, r_{i}>$ $0, i=1,2, \ldots, N$. 


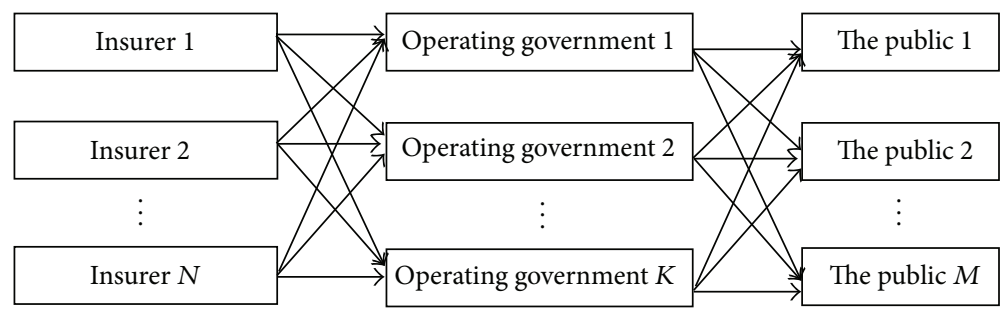

FIGURE 2: Structure of emergency financial service supply chain.

$s_{k}$ : interests of the pure growth rate for operating government $k, k=1,2, \ldots, K$.

$a_{i j}$ : contribution rate of insurer $j$ to insurer $i$.

$b_{i k}$ : contribution rate of operating government $k$ to insurer $i$.

$c_{k l}$ : contribution rate of operating government $l$ to operating government $k$.

$\beta_{k i}$ : stated social utility rate of operating government $k$ to insurer $i$.

$\gamma_{k m}$ : stated social utility rate of operating government $k$ to the public $m$.

Definition 1. Suppose one continuous-dynamic system on open set $\Omega \subset \mathbb{R}^{n}$ :

$$
\frac{d y_{k}}{d t}=G_{k}\left(y_{1}, y_{2}, \ldots, y_{K}\right), \quad k=1,2, \ldots, K
$$

Here the functions $G_{k}\left(y_{1}, y_{2}, \ldots, y_{K}\right), k=1,2, \ldots, K$, are continuous and have first-order partial derivative. They indicate that the relative change rate of the operating government $k$ is the function of social utility $y_{1}, y_{2}, \ldots, y_{K}$. Then we give the following definition:

Contribution rate of operating government $k$ to operating government $l$ is positive when $\partial G_{k} / \partial y_{l} \geq 0$.

Contribution rate of operating government $k$ to operating government $l$ is negative when $\partial G_{k} / \partial y_{l}<0$.

Cooperative relationship exists between operating government $k$ and operating government $l$ when $\partial G_{k} / \partial y_{l} \geq 0$ and $\partial G_{l} / \partial y_{k} \geq 0$.

Competitive relationship exists between operating government $k$ and operating government $l$ when $\left(\partial G_{k} / \partial y_{l}\right) \cdot\left(\partial G_{l} / \partial y_{k}\right)<0$.

Definition 2. Suppose one continuous-dynamic system on open set $\Omega \subset \mathbb{R}^{n}$ :

$$
\frac{d x_{i}}{d t}=F_{i}\left(x_{1}, x_{2}, \ldots, x_{N}\right), \quad i=1,2, \ldots, N
$$

Here the functions $F_{i}\left(x_{1}, x_{2}, \ldots, x_{N}\right), i=1,2, \ldots, N$, are continuous and have first-order partial derivative. They imply that the relative change rate of the insurer $i$ is the function of each profit $x_{1}, x_{2}, \ldots, x_{N}$ of insurers. Then we give the following definition:
Contribution rate of insurer $i$ to insurer $j$ is positive when $\partial F_{i} / \partial x_{j} \geq 0$.

Contribution rate of insurer $i$ to insurer $j$ is negative when $\partial F_{i} / \partial x_{j}<0$.

Cooperative relationship exists between insurer $i$ and insurer $j$ when $\partial F_{i} / \partial x_{j} \geq 0$ and $\partial F_{j} / \partial x_{i} \geq 0$.

Competitive relationship exists between insurer $i$ and insurer $j$ when $\left(\partial F_{i} / \partial x_{j}\right) \cdot\left(\partial F_{j} / \partial x_{i}\right)<0$.

According to the definition above, the different conditions of cooperative relationship among the operating governments are given in Lemma 3 and Theorem 4, and the conditions of the competitive relationship among the insurers are shown in the following conclusions.

Lemma 3. For the operating government $k, k=1,2, \ldots, K$, we assume that social utility $y_{k}\left(y_{k}>0\right)$ has first partial derivative on set $\left[t_{0}, t_{1}\right]$. The relative increasing rate of social utility equation is $d y_{k} / d t=y_{k}\left(s_{k}+\sum_{l=1}^{K} c_{k l} \cdot y_{l}\right)$. Cooperative relationship exists between operating government $k$ and operating government $l$ if $c_{k l} \geq 0, c_{l k} \geq 0$.

Proof. For the operating government, the time is positive. And the relative increasing rate of social utility is $\left(1 / y_{k}\right)\left(d y_{k} / d t\right)$. And the relative increasing rate of social utility for operating government $l$ to operating government $k$ is $c_{k l} \cdot y_{l}$. Therefore, the relative increasing rate of social utility for operating government $k$ equals the sum total of the pure interests increasing rate and the relative increasing rate of social utility from other operating governments to operating government $k$. This is demonstrated in the following formula:

$$
\frac{d y_{k}}{d t}=y_{k}\left(s_{k}+\sum_{l=1}^{K} c_{k l} \cdot y_{l}\right) .
$$

Let $y_{k}\left(s_{k}+\sum_{l=1}^{K} c_{k l} \cdot y_{l}\right) \triangleq G_{k}\left(y_{1}, y_{2}, \ldots, y_{K}\right)$. According to Definition 1 , when $\partial G_{k} / \partial y_{l} \geq 0$ and $\partial G_{l} / \partial y_{k} \geq 0$ are satisfied, the cooperative relationship among operating governments exists. So, if $c_{k l} \geq 0, c_{l k} \geq 0$, the cooperative relationship exists between the operating governments $k$ and $l$.

If every two operating governments do cooperate among all the governments, the cooperative relationships do exist. And the decision variable $c_{k l}$ does not change with time. That 
is to say, for (3), there is one equilibrium solution on open set $\left[t_{0}, t_{1}\right]$ :

$$
\begin{aligned}
& \because y_{k}>0, \\
& \therefore s_{k}+\sum_{l=1}^{K} c_{k l} \cdot y_{l}=0, \\
& \therefore \sum_{l=1}^{K} c_{k l} \cdot y_{l}=-s_{k} .
\end{aligned}
$$

Let $C=\left(c_{k l}\right)_{K \times K}, s=\left(-s_{1},-s_{2}, \ldots,-s_{K}\right)^{T}$, and $y=$ $\left(y_{1}, y_{2}, \ldots, y_{K}\right)^{T}$.

Thus, (3) can be transformed into the following formula:

$$
C y=s .
$$

Theorem 4. $y^{*}=C^{-1} \mathcal{S}=\left[\begin{array}{c}y_{1}^{*} \\ y_{2}^{*} \\ \vdots \\ y_{K}^{*}\end{array}\right]$ is asymptotically stable if characteristic roots of $J_{1}=\left(\partial G_{k} / \partial y_{l}\right)_{K \times K \mid y_{k}=y_{k}^{*}}$ have negative real parts in (5) when $|C| \neq 0$.

Proof. The equilibrium solution is discussed in (3). The equilibrium solution exists in (3). $c_{k l}$ does not change with time. And $y^{*}$ is the equilibrium solution which satisfies $G_{k}\left(y^{*}\right)=$ $0, k=1,2, \ldots, K$.

When $|C|=0$, there exists a solution space of (3) which shows that many equilibrium solutions exist in (5).

When $|C| \neq 0$, there exists only one equilibrium solution. And the solution is $y^{*}=C^{-1} s$.

In order to take into account the stability of the equilibrium solution, the Jacobian Matrix of (5) in $y^{*}$ is discussed in the following:

$$
\begin{aligned}
J_{1} & =\left(\frac{\partial G_{k}}{\partial y_{l}}\right)_{K \times K \mid y_{k}=y_{k}^{*}}, \\
\left.\frac{\partial G_{k}}{\partial y_{l}}\right|_{y_{k}=y_{k}^{*}} & = \begin{cases}y_{k}^{*} c_{k l}, & k \neq l, \\
s_{k}+c_{k l} y_{k}^{*}+\sum_{l=1}^{K} c_{k l} y_{k}^{*}, & k=l .\end{cases}
\end{aligned}
$$

The social utility $y_{k}^{*}\left(y_{k}^{*}>0, k=1,2, \ldots, K\right)$ affects both the insurers and the public. If $y^{*}=C^{-1} s$ are asymptotically stable, characteristic roots of $J_{1}=\left(\partial G_{k} / \partial y_{l}\right)_{K \times K \mid y_{k}=y_{k}^{*}}$ should have negative real parts when $|C| \neq 0$.

Lemma 5. For insurer $i$, we assume that the profit function $x_{i}\left(x_{i}>0\right)$ has first derivative on $\left[t_{0}, t_{1}\right]$. The differential dynamic equation of profit for insurer i is $d x_{i} / d t=x_{i} \cdot\left(r_{i}+\sum_{j=1}^{N} a_{i j} \cdot\right.$ $\left.x_{j}+\sum_{k=1}^{K} b_{i k} \cdot y_{k}^{*} \cdot \beta_{k i}\right)$. Competitive relationship exists between insurer $i$ and insurer $j$ when $a_{i j} \cdot a_{j i}<0$.

Proof. The equilibrium solution of the $k$ th operating government is $y_{k}^{*}$. Assume that $\beta_{k i}$ is the stated social utility rate of operating government $k$ to insurer $i . \gamma_{k m}$ is the stated social utility rate of operating government $k$ to the public $m$ according to the government budget and the extent of damage of the natural disaster. Therefore, the social utility of operating government $k$ to insurer $i$ is $y_{k}^{*} \cdot \beta_{k i}$ when the equilibrium solution exists where $\sum_{i=1}^{N} \beta_{k i}=1$. And the social utility of operating government $k$ to the public $m$ is $y_{k}^{*} \cdot \gamma_{k m}$.

The relative growth rate of profit $x_{i}$ comes from both the insurer and the operating government. Therefore, the differential dynamic equation of profit for insurers is shown in the following:

$$
\begin{aligned}
\frac{1}{x_{i}} \frac{d x_{i}}{d t} & =r_{i}+\sum_{j=1}^{N} a_{i j} \cdot x_{j}+\sum_{k=1}^{K} b_{i k} \cdot y_{k}^{*} \cdot \beta_{k i}, \\
\frac{d x_{i}}{d t} & =x_{i} \cdot\left(r_{i}+\sum_{j=1}^{N} a_{i j} \cdot x_{j}+\sum_{k=1}^{K} b_{i k} \cdot y_{k}^{*} \cdot \beta_{k i}\right) .
\end{aligned}
$$

Let $x_{i} \cdot\left(r_{i}+\sum_{j=1}^{N} a_{i j} \cdot x_{j}+\sum_{k=1}^{K} b_{i k} \cdot y_{k}^{*} \cdot \beta_{k i}\right) \triangleq F_{i}\left(x_{1}, x_{2}, \ldots, x_{N}\right)$.

Because $\left(\partial F_{i} / \partial x_{j}\right) \cdot\left(\partial F_{j} / \partial x_{i}\right)<0 \Rightarrow a_{i j} \cdot a_{j i}<0$, the competitive relationships exist among insurance companies.

If every two insurers do compete among all the insurers, the competitive relationships do exist for all insurers. That is to say, there is one equilibrium solution existing in (7) and $a_{i j}$ does not change with time:

$$
\begin{aligned}
& \because x_{i}>0, \\
& \therefore r_{i}+\sum_{j=1}^{N} a_{i j} \cdot x_{j}+\sum_{k=1}^{K} b_{i k} \cdot y_{k}^{*} \cdot \beta_{k i}=0, \\
& \therefore \sum_{j=1}^{N} a_{i j} \cdot x_{j}=-r_{i}-\sum_{k=1}^{K} b_{i k} \cdot y_{k}^{*} \cdot \beta_{k i} .
\end{aligned}
$$

Let $A=\left(a_{i j}\right)_{N \times N}$; then

$$
\begin{aligned}
r= & \left(-r_{1}-\sum_{k=1}^{K} b_{1 k} \cdot y_{k}^{*} \cdot \beta_{k i},-r_{2}-\sum_{k=1}^{K} b_{2 k} \cdot y_{k}^{*} \cdot \beta_{k i}, \ldots,\right. \\
& \left.-r_{N}-\sum_{k=1}^{K} b_{N k} \cdot y_{k}^{*} \cdot \beta_{k i}\right)^{T}, \\
x & =\left(x_{1}, x_{2}, \ldots, x_{N}\right)^{T} .
\end{aligned}
$$

Equation (7) can be transformed into the following formula:

$$
A x=r .
$$

Theorem 6. $x^{*}=A^{-1} r=\left[\begin{array}{c}x_{1}^{*} \\ x_{2}^{*} \\ \vdots \\ x_{N}^{*}\end{array}\right]$ is asymptotically stable if characteristic roots of $J_{2}=\left(\partial F_{i} / \partial x_{j}\right)_{N \times N \mid x_{j}=x_{j}^{*}}$ have negative real parts in (10) when $|A| \neq 0$. 
Proof. When $|A|=0$, there exists a solution space in (10) which shows that many equilibrium solutions exist in (10).

When $|A| \neq 0$, there exists only one real equilibrium solution. And the solution is $x^{*}=A^{-1} r$.

In order to take into consideration the stability of the equilibrium solution, the Jacobian Matrix of (7) in $x^{*}$ is employed:

$$
\begin{gathered}
J_{2}=\left(\frac{\partial F_{i}}{\partial x_{j}}\right)_{N \times N \mid x_{j}=x_{j}^{*}}, \\
\left.\frac{\partial F_{i}}{\partial x_{j}}\right|_{x_{j}=x_{j}^{*}}= \begin{cases}x_{i}^{*} a_{i j}, & i \neq j, \\
r_{i}+a_{i j} x_{j}^{*}+\sum_{j=1}^{N} a_{i j} x_{j}^{*}, & i=j .\end{cases}
\end{gathered}
$$

And if $|A| \neq 0, J_{2}=\left(\partial F_{i} / \partial x_{j}\right)_{N \times N \mid x_{j}=x_{j}^{*}}$ should have negative real parts, and the solution $x^{*}=A^{-1} r$ is asymptotically stable.

Theorem 7. $\left(x^{*}, y^{*}, z^{*}\right)=\left(A^{-1} r, C^{-1} s,\left(\sum_{k=1}^{K} \gamma_{k 1} \cdot y_{k}^{*} \sum_{k=1}^{K} \gamma_{k 2}\right.\right.$. $\left.\left.y_{k}^{*} \cdots \sum_{k=1}^{K} \gamma_{k N} \cdot y_{k}^{*}\right)\right)$ is the equilibrium solution space among the insurers, the operating governments, and the public if the following conditions are satisfied:

(1) Characteristic roots of $J_{2}=\left(\partial F_{i} / \partial x_{j}\right)_{N \times N \mid x_{j}=x_{j}^{*}}$ have negative real parts when $|A| \neq 0$.

(2) Characteristic roots of $J_{1}=\left(\partial G_{k} / \partial y_{l}\right)_{K \times K \mid y_{k}=y_{k}^{*}}$ have negative real parts when $|C| \neq 0$.

Proof. Because we assumed that the public only receive the subsidy from the operating government before the emergency financial service supply chain working, the operating governments should set the social utility rate $\left(\beta_{k i}, \gamma_{k m}\right)$ in advance for the insurers and the public according to the budget. Consequently, the social utility of operating government $k$ to insurer $i$ when equilibrium solution exists is $y_{k}^{*} \cdot \beta_{k i}$, where $\sum_{i=1}^{N} \beta_{k i}=1$. Social utility of operating government $k$ to the public $m$ is $y_{k}^{*} \cdot \gamma_{k m}$, where $\sum_{m=1}^{M} \gamma_{k m}=1$. And the equilibrium solution space among the insurers, the operating governments, and the public is $\left(x^{*}, y^{*}, z^{*}\right)$ :

$$
\begin{aligned}
& z^{*}=\left(\sum_{k=1}^{K} \gamma_{k 1} \cdot y_{k}^{*} \sum_{k=1}^{K} \gamma_{k 2} \cdot y_{k}^{*} \cdots \sum_{k=1}^{K} \gamma_{k N} \cdot y_{k}^{*}\right), \\
& \left(x^{*}, y^{*}, z^{*}\right)=\left(A^{-1} r, C^{-1} s,\right. \\
& \left.\left(\sum_{k=1}^{K} \gamma_{k 1} \cdot y_{k}^{*} \sum_{k=1}^{K} \gamma_{k 2} \cdot y_{k}^{*} \cdots \sum_{k=1}^{K} \gamma_{k N} \cdot y_{k}^{*}\right)\right) .
\end{aligned}
$$

According to Theorems 4 and 6, this result is proved.

\section{Competing Interests}

The author declares that there is no conflict of interests regarding the publication of this paper.

\section{Acknowledgments}

This research has been funded by National Natural Science Foundation of China (no. 41101509), Humanity and Social Science Youth Foundation of Ministry of Education of China (no. 12YJC630290), and Postdoctoral Foundation of Jiangsu Province (1501048A).

\section{References}

[1] C. Benson and E. Clay, "Understanding the Economic and Financial Impact of Natural Disasters," The International Bank for Reconstruction and Development, The World Bank, Washington, DC, USA, 2004.

[2] G. Niehaus and S. V. Mann, "The trading of underwriting risk: an analysis of insurance futures contracts and reinsurance," The Journal of Risk and Insurance, vol. 59, no. 4, pp. 601-627, 1992.

[3] C. Gollier, Some Aspects of the Economics of Catastrophe Risk Insurance, vol. 1409 of Center for Economic Studies and Ifo Institute for Economic Research, 2005.

[4] J. D. Cummins, "Should the government provide insurance for catastrophes?" Federal Reserve Bank of St. Louis Review, vol. 88, no. 4, pp. 337-379, 2006.

[5] D. M. Jaffee, H. C. Kunreuther, and E. O. Michel-Kerjan, Long Term Insurance (LTI) for Addressing Catastrophe Risk, Risk Management and Decision Processes Center, The Wharton School, University of Pennsylvania, 2008.

[6] T. Ermolieva and Y. Ermoliev, "Catastrophic risk management: flood and seismic risks," IIASA RP-05-007, 2005.

[7] S. Ma, N. Lu, and L. Zhang, "Construction and optimization in emergency financial service supply chain for extreme flood disaster risk," Journal of Catastrophology, vol. 29, no. 3, pp. 52-56, 2014.

[8] Y. Paudel, "A comparative study of public-private catastrophe insurance systems: lessons from current practices," The Geneva Papers on Risk and Insurance Issues and Practice, vol. 37, no. 2, pp. 257-285, 2012.

[9] P.-J. Shi, "Theory and practice on disaster system research in a fifth time," Journal of Natural Disasters, vol. 18, no. 5, pp. 1-9, 2009.

[10] X.-T. Cheng, "Recent progress in flood and drought management research," Journal of China Institute of Water Resources and Hydropower Research, vol. 6, no. 3, pp. 191-198, 2008.

[11] X.-T. Cheng, "Promotion of flood management in India: case analysis and enlightenments," Journal of China Institute of Water Resources and Hydropower Research, vol. 8, no. 1, pp. 18-24, 2010.

[12] J.-Q. Zhang, N. Okada, and H. Tatano, "Integrated natural disaster risk management: comprehensive and integrated model and Chinese strategy choice," Journal of Natural Disasters, vol. 15 , no. 10 , pp. $29-37,2006$.

[13] Z.-M. Shan, "On establishing catastrophe insurance system in China," Insurance Studies, vol. 6, no. 4, pp. 48-49, 2006.

[14] P. Grossi and H. Kunreuther, "Catastrophe modeling: a new approach to managing risk," in An Introduction to Catastrophe Models and Insurance, P. Grossi and H. Kunreuther, Eds., pp. 23-42, Springer, New York, NY, USA, 2005.

[15] M. Ribatet, E. Sauquet, J.-M. Grésillon, and T. B. M. J. Ouarda, "A regional Bayesian POT model for flood frequency analysis," Stochastic Environmental Research and Risk Assessment, vol. 21, no. 4, pp. 327-339, 2007. 
[16] M. Akhmet and M. O. Fen, "Homoclinic and heteroclinic motions in economic models with exogenous shocks," Applied Mathematics and Nonlinear Sciences, vol. 1, no. 1, pp. 1-10, 2016.

[17] S. O. Pyskunov, Yu. V. Maksimyk, and V. V. Valer, "Finite element analysis of influence of non-homogenous temperature field on designed lifetime of spatial structural elements under creep conditions," Applied Mathematics and Nonlinear Sciences, vol. 1, no. 1, pp. 253-262, 2016.

[18] K. Sengupta, D. R. Heiser, and L. S. Cook, "Manufacturing and service supply chain performance: a comparative analysis," Journal of Supply Chain Management, vol. 42, no. 4, pp. 4-15, 2006.

[19] L. M. Ellram, W. L. Tate, and C. Billington, "Services Supply Management: the next frontier for improved organizational performance," California Management Review, vol. 49, no. 4, pp. 44-66, 2007.

[20] M. Giannakis, "Management of service supply chains with a service-oriented reference model: the case of management consulting," Supply Chain Management, vol. 16, no. 5, pp. 346-361, 2011. 


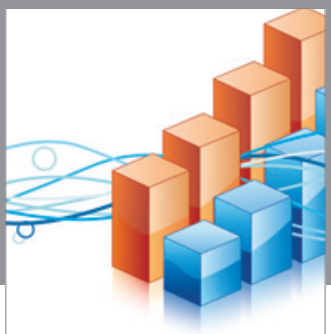

Advances in

Operations Research

vatem alat4

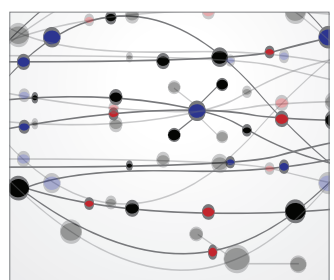

\section{The Scientific} World Journal
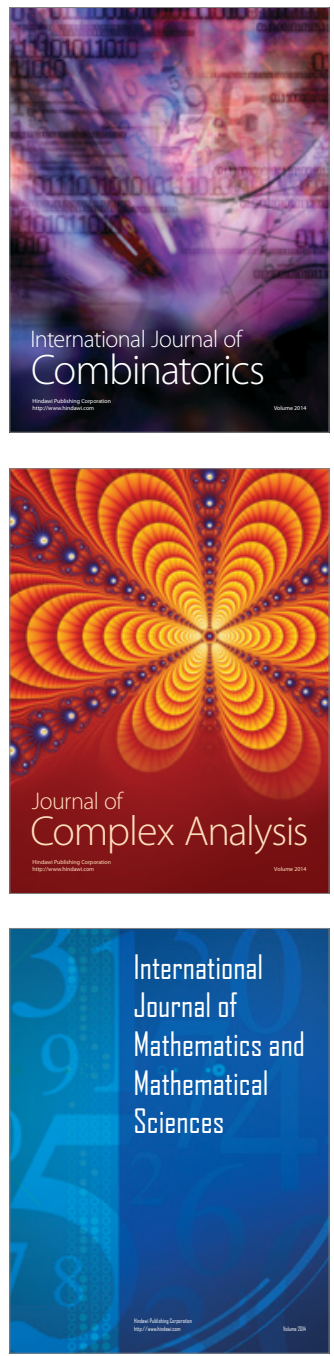
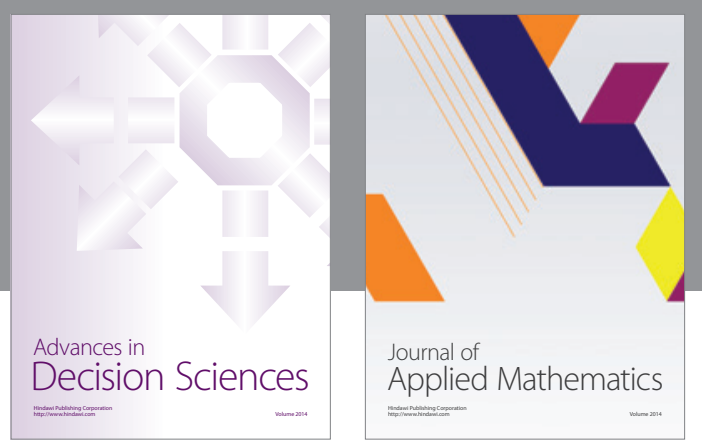

Algebra

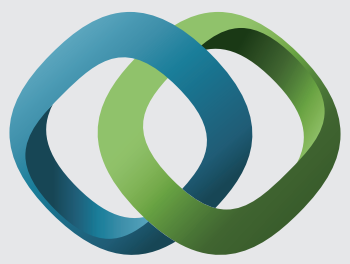

\section{Hindawi}

Submit your manuscripts at

http://www.hindawi.com
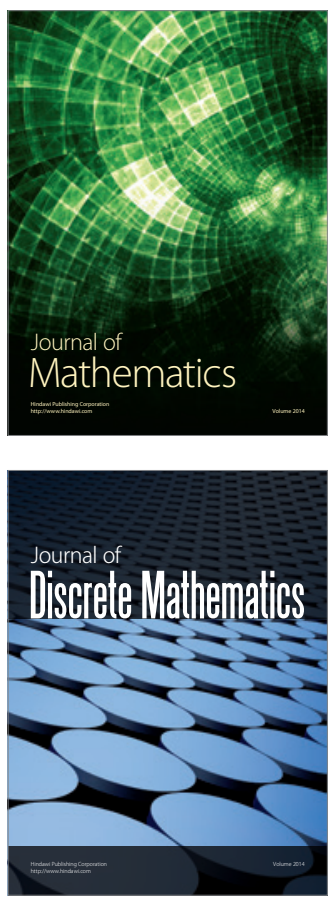

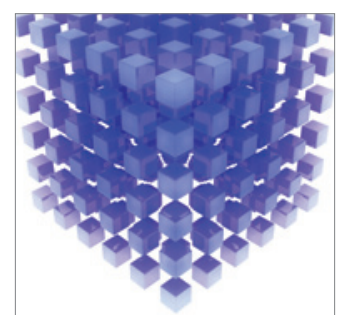

Mathematical Problems in Engineering
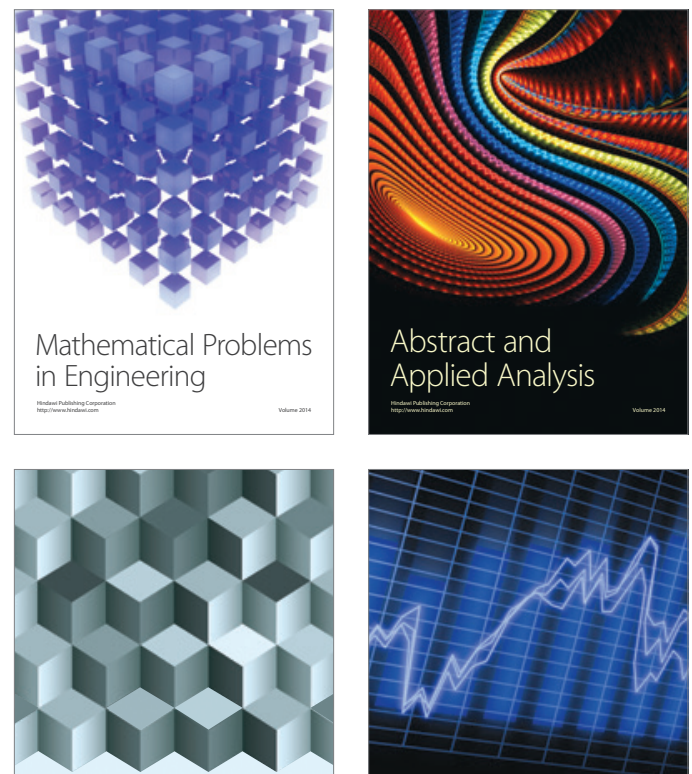

Journal of

Function Spaces

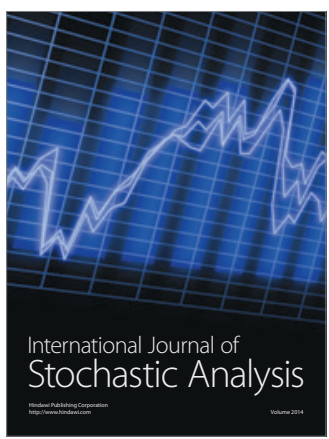

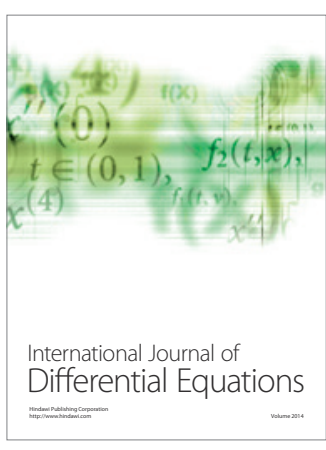
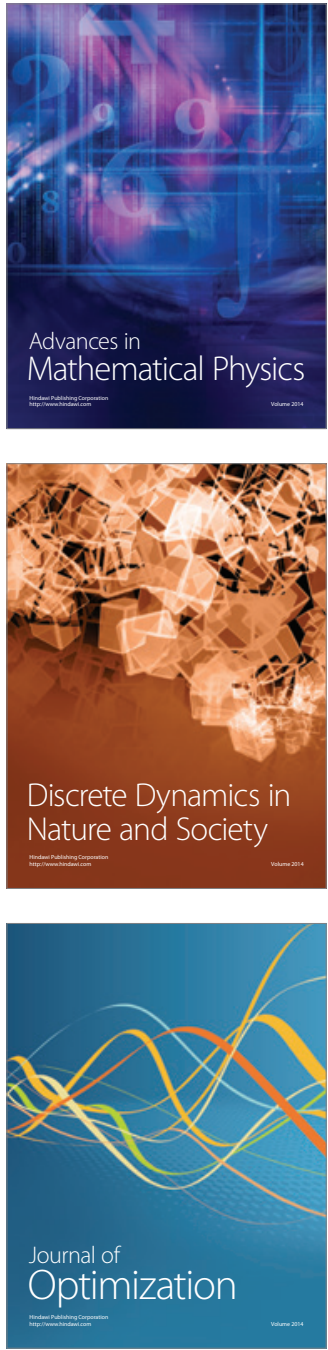